\title{
The Implicit Impact on Retail Management Education/Research in India Owing to Favoritism in the Recruitment of Faculty Members at IIMs, IITs, NITs, IIITs, IISc, and NITIE
}

\author{
H. R. Ganesha ${ }^{1} \&$ P. S. Aithal ${ }^{2}$ \\ ${ }^{1}$ CEO - Consulting Division, Gramss Retail Trading Private Limited, Bengaluru, India, and \\ Post-Doctoral Research Fellow at the College of Management \& Commerce, Srinivas University, \\ Mangalore, India. \\ OrcidID: 0000-0002-5878-8844; E-mail: hrganesha@yahoo.co.in \\ ${ }^{2}$ Vice Chancellor, Srinivas University, Mangalore, India. \\ OrcidID: 0000-0002-4691-8736; E-mail: psaithal@ gmail.com
}

Area of the Paper: Business Management.

Type of the Paper: Research Paper.

Type of Review: Peer Reviewed as per $|\mathrm{C}| \mathrm{O}|\mathrm{P}| \mathrm{E} \mid$ guidance.

Indexed In: OpenAIRE.

DOI: http://doi.org/10.5281/zenodo.4064688

Google Scholar Citation: IJCSBE.

\section{How to Cite this Paper:}

Ganesha, H. R., \& Aithal, P. S. (2020). The Implicit Impact on Retail Management Education /Research in India Owing to Favoritism in the Recruitment of Faculty Members at IIMs, IITs, NITs, IIITs, IISc, and NITIE. International Journal of Case Studies in Business, IT, and Education (IJCSBE), 4(2), 153-168. DOI: http://doi.org/10.5281/zenodo.4064688

International Journal of Case Studies in Business, IT and Education (IJCSBE)

A Refereed International Journal of Srinivas University, India.

(C) With Authors.

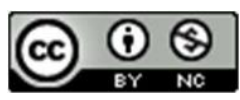

This work is licensed under a Creative Commons Attribution Non-Commercial 4.0 International License subject to proper citation to the publication source of the work.

Disclaimer: The scholarly papers as reviewed and published by the Srinivas Publications (S.P.), India are the views and opinions of their respective authors and are not the views or opinions of the S.P. The S.P. disclaims of any harm or loss caused due to the published content to any party. 


\title{
The Implicit Impact on Retail Management Education/Research in India Owing to Favoritism in the Recruitment of Faculty Members at IIMs, IITs, NITs, IIITs, IISc, and NITIE
}

\author{
H. R. Ganesha ${ }^{1} \&$ P. S. Aithal ${ }^{2}$ \\ ${ }^{1}$ CEO - Consulting Division, Gramss Retail Trading Private Limited, Bengaluru, India, and \\ Post-Doctoral Research Fellow at the College of Management \& Commerce, Srinivas University, \\ Mangalore, India. \\ OrcidID: 0000-0002-5878-8844; E-mail: hrganesha@yahoo.co.in \\ ${ }^{2}$ Vice Chancellor, Srinivas University, Mangalore, India. \\ OrcidID: 0000-0002-4691-8736; E-mail: psaithal@gmail.com
}

\begin{abstract}
Among about 993 universities and approximately 50,000 higher education institutions (HIEs) in India, the Government of India (GoI) has identified a few institutes and accorded them Institutes of National Importance (INI) status. The key assumption was that these institutes would set higher quality standards for other HEIs in the country by delivering world-class research output that is capable of contributing to the overall social and economic development of the country by choosing the research areas that demonstrate National level importance. Undoubtedly, Retail Management education/research is one such area. Besides, these institutes would adopt unbiased practices in the process of student's admission and recruitment of faculty members that would set higher quality standards for other HEIs to follow. It is evident that these institutes have adopted a transparent and unbiased practice in admitting students, but there is no evidence of such practice in the process of recruitment of faculty members. In this study, we have evaluated the research interests of 1,361 faculty members working in the Department of Management Studies of these institutes. Going by the definition of favoritism by Arasli and Tumer (2008), that is, "the provision of special privilege to friends, colleagues, and acquaintances, in areas of employment, career and personnel decisions," the results indicate a significant level of favoritism in the recruitment of faculty members at these institutes and this practice whether or not adopted consciously is implicitly affecting the Retail Management education/research in India negatively.
\end{abstract}

Keywords: Indian Retail; Retail Management; Retail Education; Retail Research; IIM; IIT; NIT; IIIT; IISc; NITIE; Institutes of National Importance; Favouritism; Faculty Recruitment.

\section{INTRODUCTION:}

India, being a growing liberal country for educational reforms, currently has about 993 universities and approximately 50,000 higher education institutions (HIEs), reflecting the high fragmentation and many smallsized HEIs in the country [1]. It is found that over $40 \%$ of these small-sized institutions are running a single program against the expected reform to a multidisciplinary style of higher education, which is an essential requirement for the educational reforms in the country for the Twenty-First century [2]. It is also noted that over $20 \%$ of colleges have annual enrolment of less than 100 students making them nonviable to improve the quality of education and only $4 \%$ of colleges enroll more than 3,000 students annually due to regional imbalance as well as the quality of education they offer [3]. It is predicted that India will be the third-largest economy in the world by the year 2030 with an estimated gross domestic product (GDP) of ten trillion U.S. dollars and this will be driven by knowledge resources and not by the natural resources of the country. To 


\section{International Journal of Case Studies in Business, IT, and Education $\quad$ SRINIVAS (IJCSBE), ISSN: 2581-6942, Vol. 4, No. 2, October 2020. PUBLICATION}

boost the growth of the Indian education sector, the present government decided to revamp it by introducing a comprehensive National Education Policy [NEP] 2020. This is in line with the Prime Minister's recent call on leveraging the Fourth Industrial Revolution to take India to new heights. The currently introduced NEP 2020 envisions an India centered education system that contributes directly to transforming our nation sustainably into an equitable and vibrant knowledge society by providing high-quality education to all [4]. The first NEP after independence was announced in the year 1968 and the second national education policy, which was an improved version of the first was announced in the year 1986.

Among such a humungous number of HEIs, the Government of India (GoI) has identified a few institutes and grouped them into Institutes of National Importance (INI), which is a special status that is conferred on a premier public HEI in India. INIs are expected to play an important and pivotal role in developing highly skilled personnel within the specified region of the country or state in addition to receiving special recognition and funding from the GoI. The INIs include 20 IIMs (Indian Institute of Management), 23 IITs (Indian Institute of Technology), and 32 NITs (National Institute of Technology) [5-7]. The GoI has also instituted one IISc (Indian Institute of Science), 1 NITIE (National Institute of Industrial Engineering), and 25 IIITs (Indian Institute of Information Technology). Of these 15 IITs, 14 NITs, and 22 IIITs do not have a specific department for Management Studies and Research [8-58]. To narrow the focus of this study, we group all these institutes into the Indian Institutes of Special Importance (IoSI). All these institutes have also been given autonomy and are not required to follow the guidelines concerning Course, Course Structure, Course Fee, Eligibility Criteria for admission to different courses, Faculty Recruitment, Examinations, and so on set by UGC (University Grant Commission) that regulates all the Universities in India and AICTE (All India Council for Technical Education) that regulates all the institutes conducting Technical and Management courses in India. We understand that the autonomy/funding/special status is provided to these institutes to facilitate/empower them in delivering world-class Graduates in addition to producing world-class research. Undoubtedly, these Institutes are delivering world-class Graduates who are capable of competing anywhere in the world and we attribute this success to the rigorous student selection criteria adopted by the IoSI that by default ensures admitting only the top $1 \%$ of students in the country. However, the faculty members at the IoSI fail to show higher-levels of research performance at an international level [59-61].

\section{PURPOSE AND OBJECTIVES:}

The overall market size of the Indian retail industry that was 950 billion USD in the year 2018 of which $97 \%$ was from brick-and-mortar (B\&M) retailing is forecast to reach 1.75 trillion USD by the year 2026. In other words, at present, about $10 \%$ of the nominal GDP of India is contributed by the retail industry in addition to accounting for $8 \%$ of employment [62]. And by the year 2030, urban agglomerations in India could lead to a) an increase in the middle-class consumer segment by 3 times compared to the year 2010 which was at 22 million, b) an increase in the number of people living in urban cities to 590 million, and most importantly c) an increase in cities with more than one million population to 68 [63]. India is also one of the most soughtafter countries for retailing opportunities globally, mainly because of the higher population consisting of the relatively younger population and higher penetration of internet users.

India is one of the largest countries with consumers belonging to the widest range of Religions, Regions, Languages, Cultures, Sub-Cultures, Ethnicities, and Socioeconomic backgrounds that makes it difficult for any organized B\&M retailers to service divergent needs of such consumers and also aim for taking the larger share of the retail market. It has been reported that the organized retailing in India that was at $12 \%$ of the overall retail market in the year 2017, is expected to increase to just $25 \%$ by the year 2021 that is way too low in comparison with a majority of developing and developed countries [64]. Another reality is, over $80 \%$ of unorganized/small-scale B\&M retailing in India is run by family-owned business houses that represent 9.6 million stores, and this is the largest number of small-scale stores present in a country! [65]. Traditional retailing formats were perceived to be inefficient and weak in various aspects and hence successful modernization policies to be implemented in countries having the majority of retailing in the unorganized form [66]. The hard reality is that India is yet to witness a successful large-scale organized B\&M retailer like Walmart in the USA, Schwarz in France, H\&M in Sweden, Inditex in Spain, Tesco in the UK, Fast in Japan, and so on. Moreover, even a few of these successful global retailers are also yet to witness success in the Indian market that is even harder reality. This state of retailing in India raises the following questions in our minds and encourage us to carry out this study.

(1) Why the GoI is not serious in developing policies and frameworks for the upliftment of the retailing 


\section{International Journal of Case Studies in Business, IT, and Education SRINIVAS (IJCSBE), ISSN: 2581-6942, Vol. 4, No. 2, October 2020. PUBLICATION}

industry in India? Even if the GoI has the right mindset to develop policies and frameworks, what support is being given by the IoSI through retail management education and research?

(2) Why such an issue of National importance is not an important area of research for the IoSI?

(3) How such a poor importance given by the IoSI towards enrichment of retail education and research is demotivating students, research scholars, and other institutes of Management Studies in India to pursue retail management and research?

\section{APPROACH AND METHODOLOGY:}

Step I: Intense and in-depth analysis of data available in the public domain was carried to collect data relating to various aspects of retail education and research and its state of importance in India.

Step II: A series of open-ended direct mystery interviews were conducted with the alumni, students, research scholars, and faculty members at the Management Studies Departments of a few of the IoSI selected through convenience sampling to understand their perspective and attitude towards the existing methodology of deciding on the prioritization of Courses and Research Areas of importance for the institute.

Step III: Courses and course structures of 102 IoSI along with the research interests of its faculty members data were collected from their institute's website [8-58] [67-116].

Step IV: Possible reasons for the research interests of 1,361 faculty members of the 102 IoSI was further drilled down through collecting data concerning previous associations and affiliations throughout their academic/work experience journey viz.,

- Stage 1: Under Graduation (UG)

- Stage 2: Post-Graduation (PG)

- Stage 3: Doctoral Studies (Ph.D.)

- Stage 4: Post-Doctoral Research (PDF)

- Stage 5: Previous Work Experience (WX)

Step V: Application for the faculty member position in the Retail Management and Research area was sent to a majority of the IoSI to collect the responses.

Step VI: In the last step, we analyzed the collected data to draw inferences.

\section{FINDINGS AND INSIGHTS:}

Through an in-depth search, we have found that there are less than 100 institutes in India offering Retail Management courses of which the majority of them are Private institutes and none are from the IoSI group. This indicates that only about $1.82 \%$ of Management colleges in India are promoting Retail education [117]. The IoSI being continually ranked among the top 100 institutes in India, a majority of Non-IoSI institutes invariably follow and adopt the practices of the IoSI concerning Courses, Course Structures, and Research Areas. A few of the renowned institutes offering Retail Management Courses are listed below.

- Alliance School of Business, Bangalore

- Amity Business School, Noida

- Birla Institute of Management Technology, Greater Noida

- College of Management \& Commerce, Srinivas University, Mangalore

- Footwear Design and Development Institute, Noida

- Guru Nanak Institute of Management, Delhi

- IMED, Bharati Vidyapeeth, Pune

- International Institute of Management Studies, Pune

- International School of Business Administration, Indore

- ITM Business School, Navi Mumbai

- Jagan Institute of Management Studies, Delhi

- Jaipuria Institute of Management, Lucknow

- KJ Somaiya Institute of Management Studies and Research, Mumbai

- MIT College of Management, Pune

- Narsee Monji Institute of Management Studies (NMIMS), Mumbai

- NITTE School of Management, Bangalore

- Noida International University, Greater Noida

- Prin LN Welingkar Institute of Management Development and Research, Mumbai

H. R. Ganesha, et al, (2020); www.srinivaspublication.com 
- PSGR Krishnammal College for Women, Coimbatore

- Sardar Vallabhbhai Patel International School of Textile Management, Coimbatore

- School of Management, GD Goenka University, Gurugram

- SCMS Cochin School of Business Management, Cochin

- Shri Sharada Institute of Indian Management, Delhi

- Starex University, Gurugram

- Symbiosis Institute of Management Studies, Pune

- The Presidency College, Berhampur

Based on our findings in the First Step, we tried to understand the reasons why the Department of Management Studies at the IoSI has ignored Retail Management education and research despite its importance in the overall development of the country. The following are some of our findings during a series of openended direct mystery interviews that were conducted with the alumni, students, research scholars, and faculty members of the Department of Management Studies of a few of the IoSI.

- Courses, Course Structures, and Research areas are determined based on the importance level at the International level and not at the National level.

- Courses and Research concerning B\&M Retail is not an area of importance internationally. However, there is some importance given to the Online/Digital Retail area.

- The majority of Retailing in India is unorganized and significantly skewed towards B\&M retailing.

- Only a few conglomerates in India are ventured into retailing which makes it difficult for us to guarantee highly paid jobs for the students at the IoSI in case we institute a specialization in Retail Management. At best, the Marketing Management specialization offered at the IoSI deals with Retail Management as one of the subjects taught.

- Unlike developed countries, a very little amount of data concerning retailing in India is available in the public domain. This means a longer duration is required to be spent for data collection and carrying out research that makes research in the B\&M retailing area furthermore unimportant.

- Research areas and work need to be aligned with current and most trending topics internationally.

- Research output in the journals of international repute is one of the key determinants of faculty member's performance evaluation and career growth at the IoSI that makes it furthermore important to align the research work with trending topics otherwise the acceptance level of research papers at such journals is very low.

- One of the important criteria while recruiting faculty members at the IoSI is their area of research interest that is expected to be aligned with the institute's priority of research areas.

- Even if a faculty member is personally interested in researching the area of Retailing, the peer pressure at the IoSI does not motivate such faculty members to pursue it further seriously.

- Another important criterion for the IoSI to consider any specific research area is determined by its ability to convert such research work into a potential Consulting Project for a Conglomerate, GoI, and firms run by the GoI.

- Improving the National and International level institute ranking is very important. As most of the ranking frameworks including NIRF (National Institute Ranking Framework) that is administered by the GoI, measure an institute's performance based on students placement, collaborative performance, and overall research output (measured by the Indexing agencies managed by International Agencies) it makes it furthermore important for the IoSI to focus on Courses, Course Structure, and Research areas that would guarantee higher levels of performance in these areas of measures.

In a nutshell, student placement, faculty member's career growth, and the institution's ranking are of key importance to the IoSI. Even though the Retail Education/Research is an area of National importance, the IoSI cannot give due importance as the same is not aligned with International importance. Even if the IoSI desires to give due importance to the Retail Education/Research, they cannot, as the same would pull them down in the rankings Nationally and Internationally owing to ranking frameworks that do not consider the contribution of institutes in the overall economic and social development of a country to which an institute belongs to.

The Third Step in this study was to collect details of the faculty members at the IoSI to further drill down using primary data thereby finding answers to our key questions. Surprisingly, only $14.55 \%$ of the faculty members were involved in the area of Marketing Management research and as hypothesized by us only 11 faculty members $(0.81 \%)$ were involved in the research of Retail Management. The research area-wise 
distribution of faculty members is shown in Chart 1 . Another finding corroborating with insights from our exploratory study is that about half of the faculty members (601) were involved in research areas viz., Organizational Behavior and Human Resource Management; Finance and Accounting; Economics and Public Policy, that would potentially guarantee them Consulting Projects from the GoI, and firms run by the GoI.

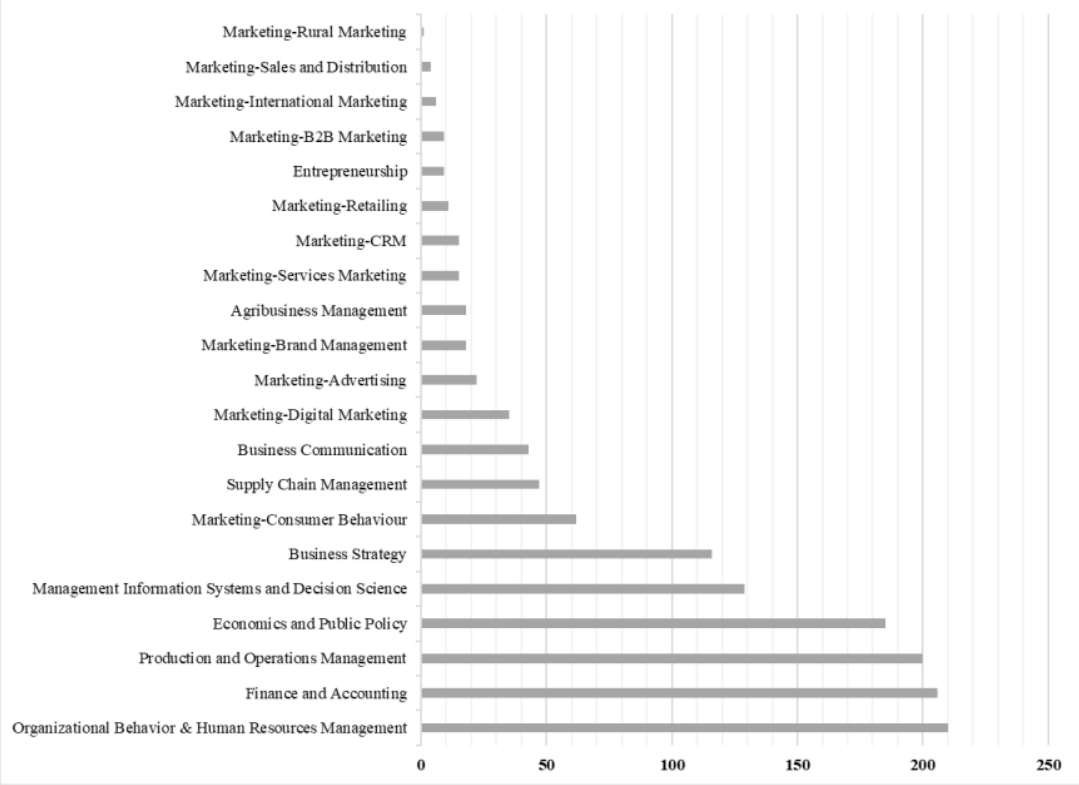

Chart 1: Distribution of 1,361 faculty members by research areas

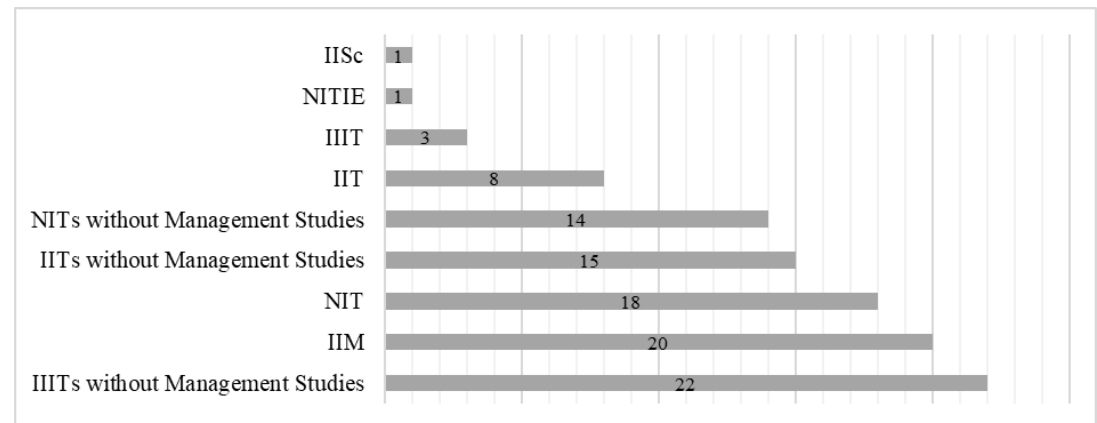

Chart 2: Number of colleges with and without management studies by institute group

It is noted that, of the 102 IoSI, we found details of 1,361 faculty members working in the Department of Management Studies at 51 institutes and other 51 institutes were not offering any degrees in the Management Studies area as shown in Chart 2.

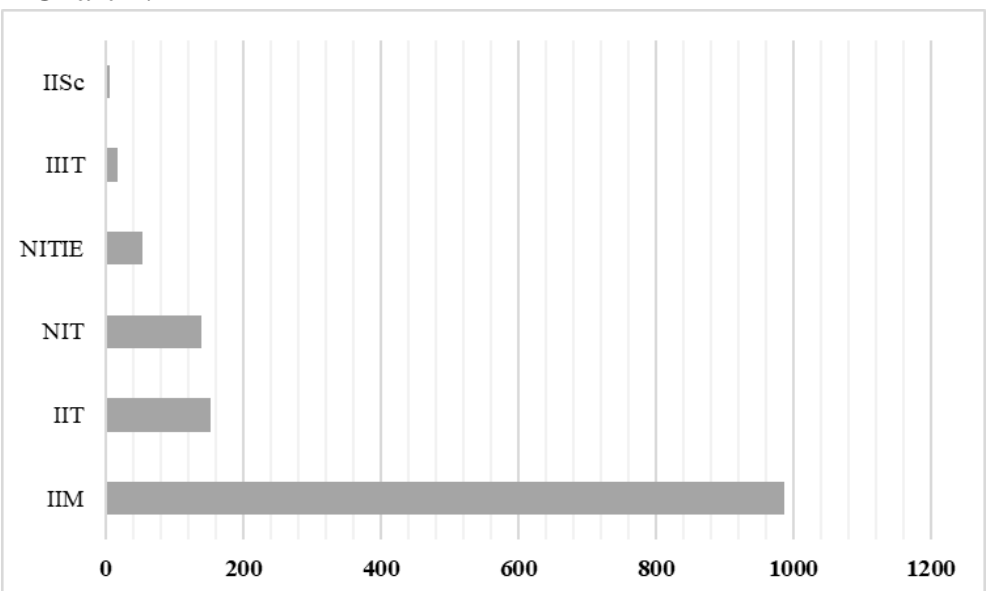

Chart 3: Distribution of 1,361 faculty members by institute group 


\section{International Journal of Case Studies in Business, IT, and Education $\quad$ SRINIVAS (IJCSBE), ISSN: 2581-6942, Vol. 4, No. 2, October 2020. PUBLICATION}

Chart 3 indicates the distribution of 1,361 faculty members at each of these IoSI. About $72.52 \%$ of the faculty members are working at IIMs followed by $11.32 \%$ at IITs, $10.29 \%$ at NITs, and balance at IIITs, NITIE, and IISc.

The Fourth Step was to evaluate the data collected for 1,361 faculty members working at the IoSI to understand these faculty member's previous association/affiliation throughout their academic/work experience journey viz., UG, PG, Ph.D., PDF, and WX. For this evaluation, in addition to tagging IIMs, IITs, NITs, IIITs, NITIE, and IISc, all the other institutes were categorized into four more groups such as;

- Institutes/Universities run by the GoI (Central Institutes and Universities)

- Non-IoSI (Institutes/Universities run by the State Governments and Private Organizations)

- All the International Institutes/Universities and Reputed National Institutes and Universities viz., BITS Pilani, VJTI Mumbai, BIT Mesra, BIT Sindri, Universities of Agricultural and Veterinary Sciences, VIT Vellore, ICT Mumbai, IoE Pune, IoE Guindy, XLRI Jamshedpur, SIBM Pune, MICA Ahmedabad, MDI Gurgaon, Madras School of Economics, IMI Delhi, TISS Mumbai, XISS Ranchi, XIM Bhubaneshwar, JBIMS Mumbai, SPJIMR Mumbai, KJSIMSR Mumbai, IMT Ghaziabad, BIM Trichy, NMIMS Mumbai, IPE Hyderabad, IFMR Chennai, Chennai Mathematical Institute, GLIM Chennai, TAPMI Mangalore, GIM Goa, FORE Delhi, and Bharatiya Vidya Bhavan Mumbai)

- Firms run by the GoI.

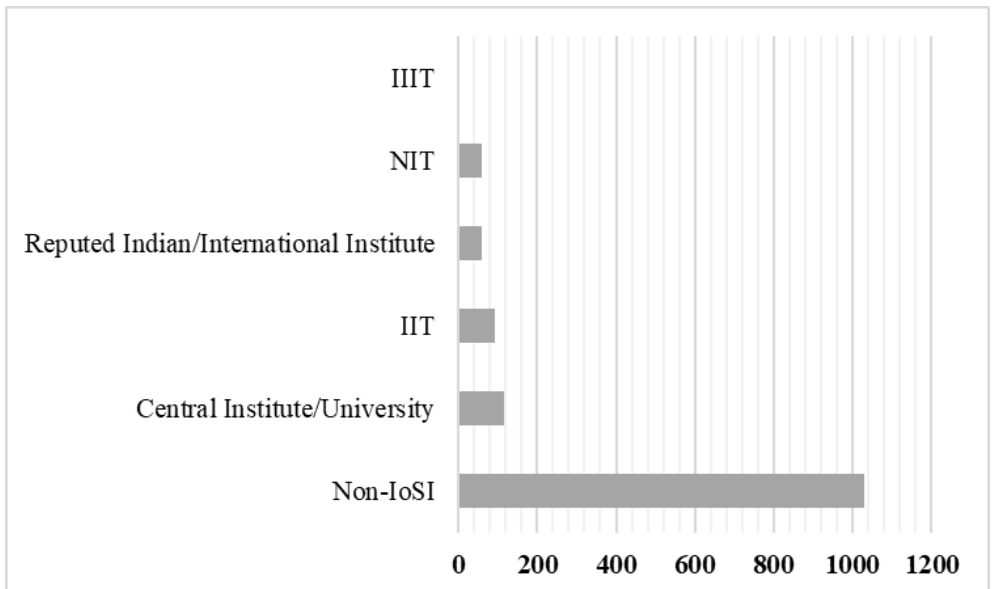

Chart 4: Affiliation of 1,361 faculty members during their under-graduation

It is observed that a significant number $(75.68 \%)$ of faculty members at the IoSI completed their UG degree from the Non-IoSI as shown in Chart 4. This is obvious as a majority of the IoSI do not offer UG programs in the Management Studies area. About 331 faculty members were found associated/affiliated with institutes other than the Non-IoSI during their UG degree.

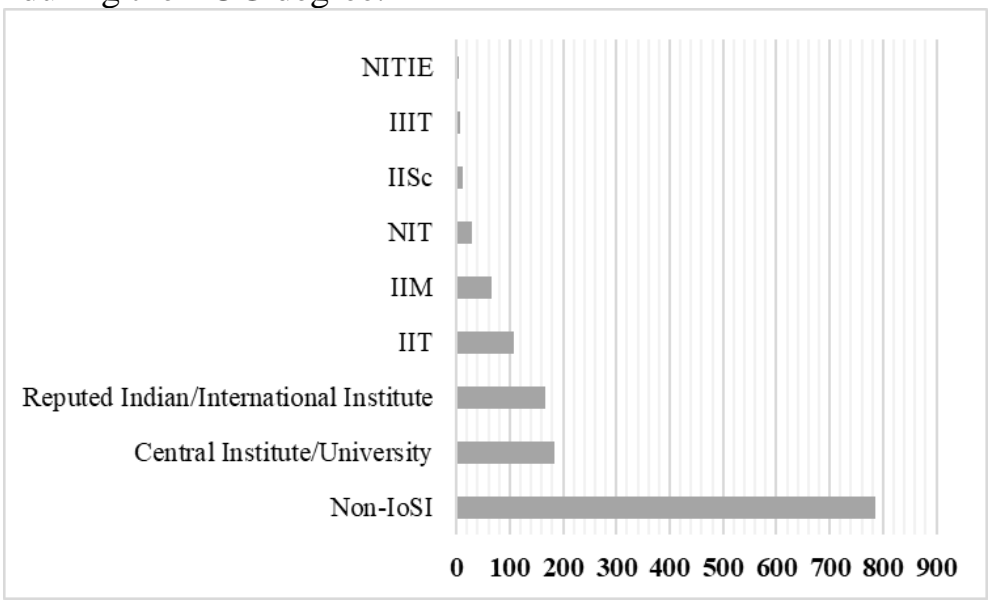

Chart 5: Affiliation of 1,361 faculty members during their post-graduation

About $57.68 \%$ of faculty members at the IoSI completed their PG degree from the Non-IoSI followed by $16.61 \%$ from the IoSI, and $13.52 \%$ from Central Institutes/Universities as shown in Chart 5 . About 576 faculty members were found associated/affiliated with institutes other than the Non-IoSI during their PG degree. 


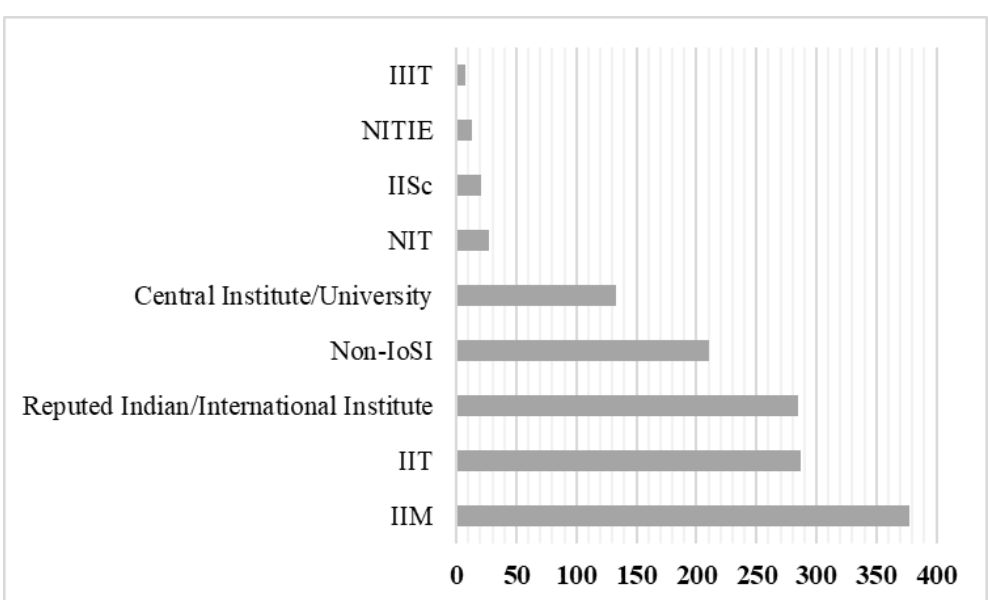

Chart 6: Affiliation of 1,361 faculty members during their doctorate

Almost half of the faculty members were found to be completed their Doctoral degree from the IoSI followed by $20.94 \%$ from the Reputed National and International Institutes/Universities, 9.77\% from the Central Institutes/Universities, and only about $15.43 \%$ from the Non-IoSI as shown in Chart 6 . About 1151 faculty members were found associated/affiliated with institutes other than the Non-IoSI during their Doctorate.

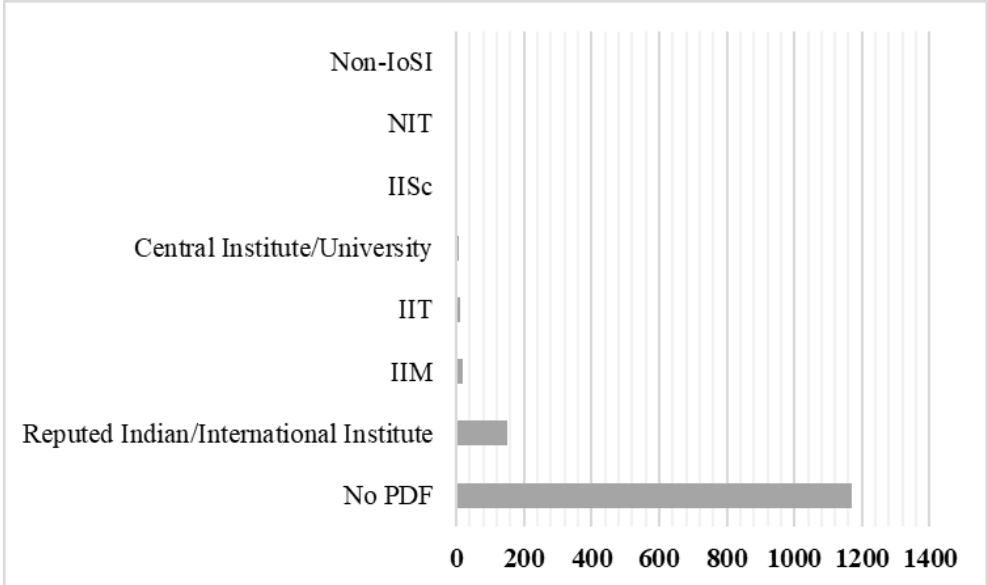

Chart 7: Affiliation of 1,361 faculty members during their post-doctorate research

Glaringly a significant number $(85.97 \%)$ of faculty members have not indicated any Post-Doctoral Research experience followed by $10.95 \%$ having PDF experience from Reputed National and International Institutes/Universities as shown in Chart 7. About 190 faculty members were found associated/affiliated with institutes other than the Non-IoSI during their PDF. Post-Doctoral research experience is an important milestone in the journey of a faculty member concerning their exposure to research activities outside their $\mathrm{Ph} . \mathrm{D}$. institution, collaboration with Industry, and most importantly a stress-free environment usually provided to PDF scholars, unlike a Ph.D. 


\section{International Journal of Case Studies in Business, IT, and Education $\quad$ SRINIVAS (IJCSBE), ISSN: 2581-6942, Vol. 4, No. 2, October 2020. PUBLICATION}

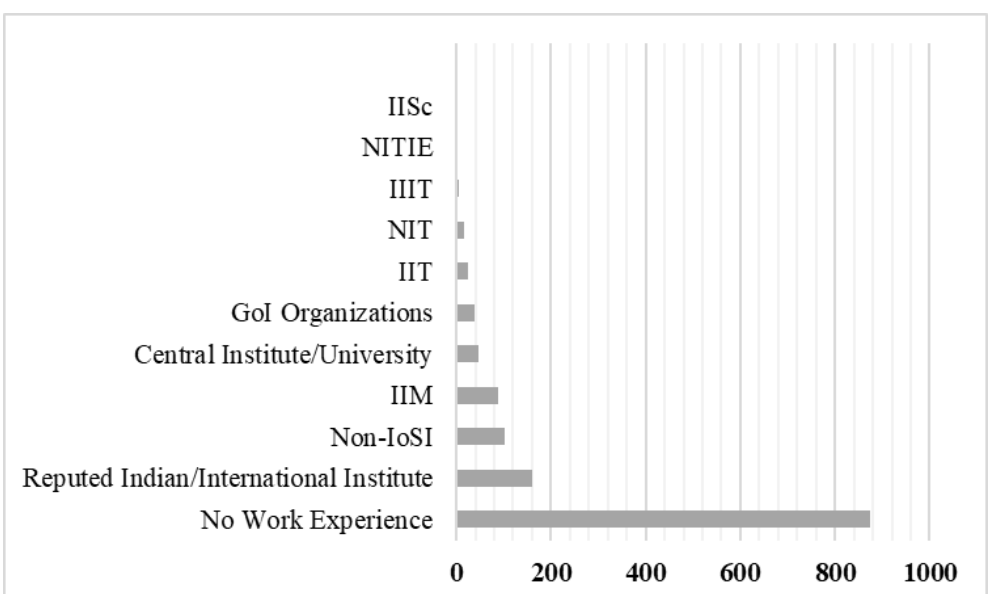

Chart 8: Affiliation of 1,361 faculty members during their previous work experience

Another glaring observation was a significant number $(64.29 \%)$ of faculty members did not have previous work experience followed by $11.68 \%$ worked at Reputed National and International Institutes/Universities, $10.07 \%$ worked at the IoSI, 3.53\% worked at Central Institutes/Universities, and $2.87 \%$ worked at Organizations run by the GoI as shown in Chart 8 . About 383 faculty members were found associated/affiliated with institutes other than the Non-IoSI during their previous work experience. The importance of previous work experience in Industry/Research/Training/Teaching is completely ignored by the IoSI which in other ways indicates that the IoSI strongly not believe in recruiting faculty members with higher levels of previous work experience that might probably make it difficult to align such faulty members to the current areas of research carried out at the IoSI.

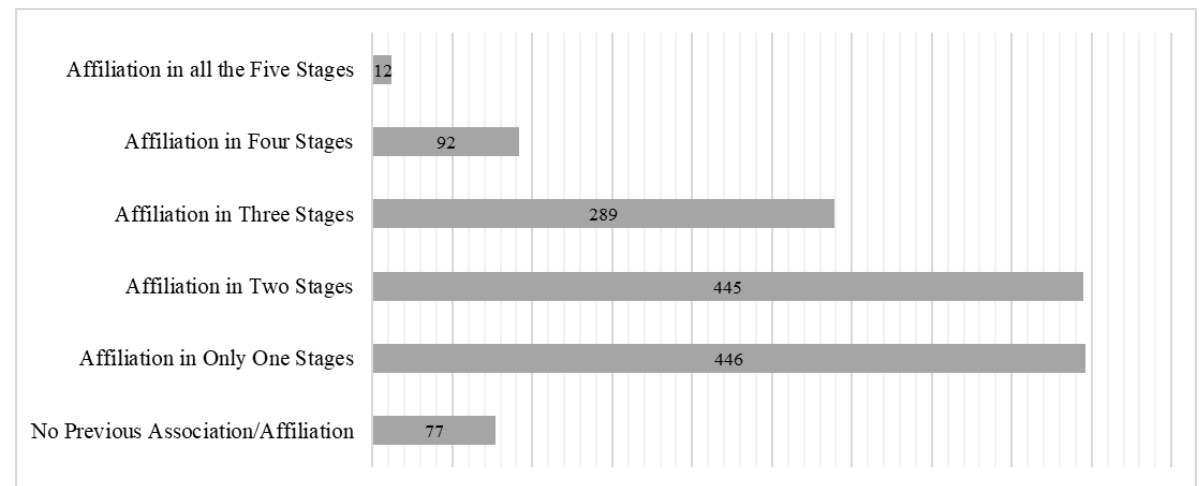

Chart 9: Number of faculty members and their previous association/affiliation

Chart 9 and 10 demonstrate that an insignificant number (77 out of 1,361 i.e., 5.66\%) of faculty members currently working at the IoSI did not have any previous association/affiliation with the Non-IoSI at any point of their journey before getting associated with the IoSI. It was also found that a majority of these 77 faculty members have joined the IoSI at the early stages when there were just a few of the IoSI producing faculty members in the Management Studies discipline. About $66.50 \%$ of faculty members had previous association/affiliation with one of the IoSI during one/more of the stages of their journey followed by $15.06 \%$ with Central Institutes/Universities/GoI, $12.78 \%$ with Reputed National and International Institutes/Universities. 


\section{International Journal of Case Studies in Business, IT, and Education $\quad$ SRINIVAS (IJCSBE), ISSN: 2581-6942, Vol. 4, No. 2, October 2020. PUBLICATION}

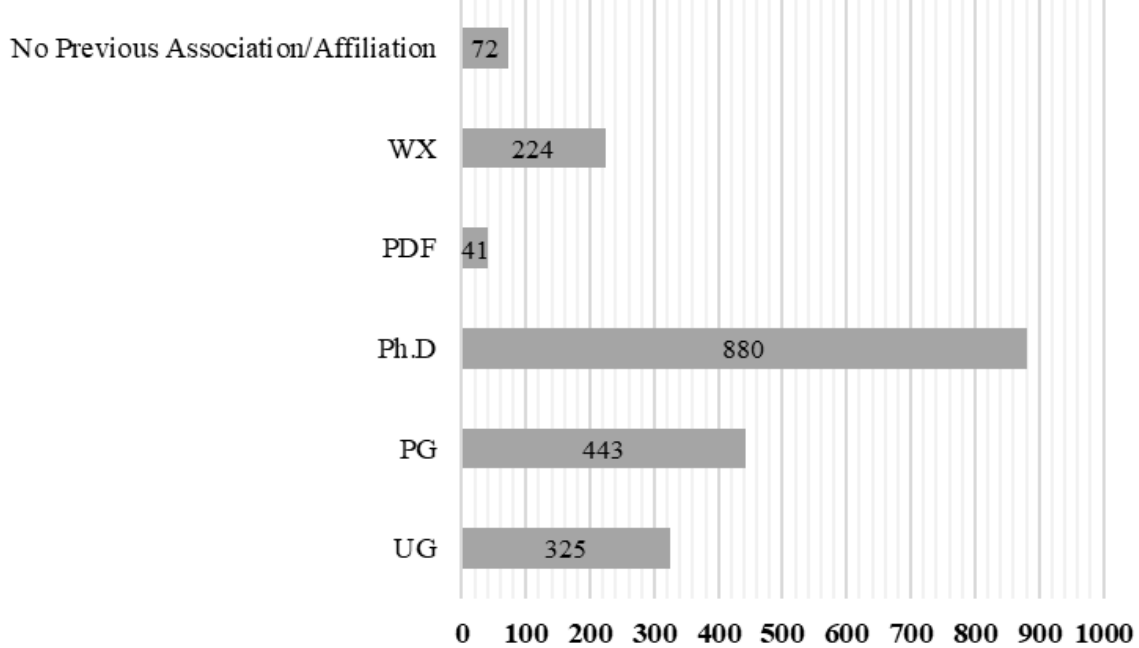

Chart 10: Number of faculty members and their previous association/affiliation by stages

Finally, Table 1 indicates a positive but insignificant association and determination between an applicant's association/affiliation with institutes other than Non-IoSI and the probability of applicant's selection for the faculty member role at the IoSI. Even if the applicant can show an association/affiliation with any one of the Non-IoSI during any one of his/her stages of the academic journey does increase the probability of selection at the IoSI. In other words, rather than an applicant's previous experience, exposure, academic diversity, and the capability to research the areas of National importance, the IoSI preferred to select an applicant who had previous association/affiliation with institutes other than the Non-IoSI.

Table 1: Association and determination of stage-wise association/affiliation of faculty members with the probability of their selection at the IoSI

\begin{tabular}{|c|l|c|c|c|c|c|}
\hline Model Predictors & Dependent Variable & $\mathbf{R}$ & $\begin{array}{c}\text { Adjusted } \\
\mathbf{R}^{2}\end{array}$ & $\begin{array}{c}\mathbf{R}^{2} \\
\text { Change }\end{array}$ & $\begin{array}{c}\text { ANOVA } \\
\text { Sig. }\end{array}$ \\
\hline 1 & Association/Affiliation in UG & & 0.095 & 0.008 & 0.009 & 0.000 \\
\hline 2 & Association/Affiliation in PG & Probability of Selection & 0.143 & 0.020 & 0.021 & 0.000 \\
\hline 3 & Association/Affiliation in Ph.D & to the Role of Faculty & 0.368 & 0.135 & 0.135 & 0.000 \\
\hline 4 & Association/Affiliation in PDF & Member at the IoSI & 0.068 & 0.004 & 0.005 & 0.011 \\
\hline 5 & Association/Affiliation in WX & & 0.105 & 0.010 & 0.011 & 0.000 \\
\hline
\end{tabular}

The Fifth Step was necessary to further investigate the criteria for faculty member's recruitment at the IoSI. Thus, applications were sent for the faculty member position at a majority of the IoSI based on the faculty requirements advertised in their institute web portal through E-Mail, Online Application Forms, and Offline Application through Post. In addition to significant research output in the Retail Management area published in Journals that are not controlled by International Publishing Agencies, the profile of the applicant indicated the area of research as Retail Management and previous association/affiliation during UG, PG, Ph.D., PDF, and WX with the Non-IoSI. About $64 \%$ of the IoSI acknowledged the receipt of the application and only about $16 \%$ informed that the candidature is not shortlisted without even a single round of discussion. All the responses were conveying the same message with different wordings as shown below.

"Thank you for your interest in a faculty position at _ _ _ _. Your CV and other supporting material were shared with the faculty of the relevant area(s). While your record is strong and your background is relevant, your interests and focus areas are not matching with our requirements as of now. Hence, we are unable to

proceed further with your application. However, we are keeping your CV on our files, and should an opportunity arise, we will get in touch with you".

\section{INFERENCE:}

First, DeAngelo et al. (2005), in one of their studies argued that "U.S. business schools are locked in a dysfunctional competition for media rankings that diverts resources from long-term knowledge creation, which earned them global pre-eminence, into short-term strategies aimed at improving their rankings. MBA curricula are distorted by a quick fix, look good packaging changes designed to influence rankings criteria, at 


\section{International Journal of Case Studies in Business, IT, and Education SRINIVAS (IJCSBE), ISSN: 2581-6942, Vol. 4, No. 2, October 2020. PUBLICATION}

the expense of giving students a rigorous, conceptual framework that will serve them well over their entire careers. Research, undergraduate education, and Ph.D. programs suffer as faculty time is diverted to almost continuous MBA curriculum changes, strategic planning exercises, and public relations efforts. Unless they wake up to the dangers of dysfunctional rankings competition, U.S. business schools are destined to lose their dominant global position and become a classic case study of how myopic decision-making begets institutional mediocrity"[119]. Based on the findings of the exploratory stage of this study (Step II), this argument holds for the IoSI too.

Second, Favoritism that is often observed in the modern economy across countries and sectors is one of the key areas of research among Social Psychologist. However, the study of favoritism as a phenomenon is a difficult task as these studies have not confirmed an unambiguous answer as to what causes favoritism?, how and when favoritism causes harm? and if it does not harm then is it useful?. Even though a majority of studies argue that the favoritism has a negative impact, a few authors argue that it is beneficial in certain cases owing to the kind of social network it builds [120], and a few argue that if the favoritism exists in an organization, it is difficult to perceive that such organizations behave ethically [121]. Though nepotism and favoritism are often considered synonymous they are not the same. Arasli and Tumer (2008), differentiate favoritism from nepotism and define favoritism as "the provision of special privilege to friends, colleagues, and acquaintances, in areas of employment, career and personnel decisions" [122]. Going by this definition, the findings of Steps III to V of this study corroborate with our hypothesis that a significantly high level of favoritism exists in the recruitment of faculty members at the IoSI.

Finally, favoritism added with the dysfunctional competition of the IoSI for rankings is leading to the ignorance of Retail Management Education/Research that is one of the significant areas of National importance for India, alongside demotivating the Non-IoSI/other HIEs too in the country in prioritizing the Retail Education/Research owing to these institutes invariably following the IoSI in prioritizing courses and areas of research.

\section{CONCLUSION AND SUGGESTIONS:}

First, we are cognizant of the fact that, just because the IoSI gets special recognition, status, autonomy, and funding from the GoI, it does not become mandatory for only the IoSI to work on the areas of National Importance. But, at the same time, the IoSI need to recognize the fact that a majority of the Non-IoSI/HEIs in the country try to imitate and follow the IoSI owing to the positive brand image being built by them over a period in the minds of Parents, Students, Research Scholars, Faculty Members, Recruiters, and Publishers. The IoSI must also recruit faculty members associated/affiliated with the Non-IoSI who are working on the research areas of National importance, otherwise they will be seriously locked in carrying out research work that is most comfortable for the existing Senior faculty members at the IoSI.

Second, The B\&M retailers in India are constantly devoting their time and money in adopting retailing theories, models, and frameworks that are practiced in developed countries that have matured markets and consumers. This is a clear example of a serious timing issue. We believe that the Indian market and consumers are moving toward the same maturity levels, but it is still a long way to go [123]. This means, thoughtful and logical integration of existing theories aligned to, the Indian market; consumer's maturity level; divergent consumer needs is crucial, and most importantly the level of National importance concerning the overall development of the country should become the core of prioritization of research areas by the IoSI and other HEIs in India. We strongly believe that the nature/magnitude of the research problems available and relevant for India coupled with 5000 years old Indian wisdom has the potential to develop new theories across management disciplines that would potentially get Global attention and enhance rankings of the IoSI and other HEIs at the International level automatically. Aligning the research areas with the requirement of International Institutes, Universities; Researchers; Publishing Agencies might increase the probability of better rankings but will seriously fail to contribute to the overall social and economic development of the country. Even if the rankings put severe pressure on the IoSI faculty members/administrators they can resist or convince the ranking agencies to change the ranking criteria. For instance, for the 2004 Business Weekly rankings both Harvard and Wharton declined to participate. We believe that the majority of the IoSI are Harvard and Wharton equivalent in India and hence they have all the necessary networks to recommend modifications to existing ranking frameworks including NIRF administered by the GoI.

Third, if the student's placement is a matter of concern to offer Courses in the Retail Management area, nothing stops the IoSI to promote research in the Retail Management area among their Research Scholars and 
Faculty members. We recommend that all the IoSI to institute a Center for Retail Research in line with the Oxford Institute of Retail Research [124] and motivate Research Scholars; Faculty Members; Practitioners, and other HEIs to contribute toward the enrichment of research in the Retail Management area that is one of the areas of National Importance for India.

Finally, the key objective of this study was not to allege the IoSI by empirically finding favoritism in the recruitment of faculty members. The key objective indeed was to highlight the implicit negative impact of such a practice at the IoSI on the overall development of the country in addition to its capability for demotivating other HEIs in India in the enrichment of Retail Education/Research. We hope that the NEP 2020 will ensure the Indian higher education system move from teacher-centric to student-centric; informationcentric to knowledge-centric; marks centric to skills-centric; examination-centric to experimental-centric; learning-centric to research-centric, and most importantly choice-centric to competency-centric [125].

\section{LIMITATIONS AND SCOPE:}

The main limitation of this study is the coverage of various stakeholders viz., the alumni, students, research scholars, and faculty members selected for the direct mystery interview of some of the IoSI. The second limitation is that the empirical validation is restricted to data available on the institute's website of the IoSI. However, it provides significant inputs concerning the existence of favoritism in the recruitment of faculty members at the IoSI and its impact on Retail Education/Research in India. We recommend researchers to adopt the methodology adopted in this study to understand the existence and impact of favoritism in other domains and sectors.

\section{REFERENCES:}

[1] https://www.mhrd.gov.in/statistics-new?shs term node tid depth=384. Retrieved in September 2020.

[2]

$$
\text { Draft National Education Policy 2019, https://innovate.mygov.in/wp- }
$$
content/uploads/2019/06/mygov15596510111.pdf

[3] Aithal, P. S. \& Aithal, Shubhrajyotsna (2019). Analysis of Higher Education in Indian National Education Policy Proposal 2019 and its Implementation Challenges. International Journal of Applied Engineering and Management Letters (IJAEML), 3(2), 1-35. DOI: http://doi.org/10.5281/Zenodo.3271330.

National

Education

Policy

https://www.mhrd.gov.in/sites/upload_files/mhrd/files/nep/NEP_Final_English.pdf

2020. 10/08/2020.

[5] https://www.mhrd.gov.in/iims. Retrieved in September 2020.

[6] https://www.mhrd.gov.in/iits. Retrieved in September 2020.

[7] https://www.mhrd.gov.in/nits. Retrieved in September 2020.

[8] https://iiitdwd.ac.in/academics.php. Retrieved in September 2020.

[9] http://iiitg.ac.in/departments.php. Retrieved in September 2020.

[10] http://iiitkalyani.ac.in/php/programmes.php. Retrieved in September 2020.

[11] http://www.iiitkota.ac.in/department. Retrieved in September 2020.

[12] https://iiitn.ac.in/departments.php. Retrieved in September 2020.

[13] https://www.iiitp.ac.in/index.php/faculty/faculty. Retrieved in September 2020.

[14] http://iiitranchi.ac.in/academics/faculty. Retrieved in September 2020.

[15] http://www.iiitmanipur.ac.in/pages/coursesOffered.html. Retrieved in September 2020.

[16] http://iiitsonepat.ac.in/academic/programmes. Retrieved in September 2020.

[17] http://www.iiits.ac.in/people/regular-faculty/. Retrieved in September 2020.

[18] http://www.iiitt.ac.in/facultypeople. Retrieved in September 2020.

[19] http://www.iiitu.ac.in/academic.html\#gsc.tab=0. Retrieved in September 2020.

H. R. Ganesha, et al, (2020); www.srinivaspublication.com 
[20] http://iiitvadodara.ac.in/faculty.php. Retrieved in September 2020.

[21] https://iiitr.ac.in/faculty.html. Retrieved in September 2020.

[22] http://www.iiitsurat.ac.in/faculty.html. Retrieved in September 2020.

[23] https://www.iiitbh.ac.in/bshfac. Retrieved in September 2020.

[24] https://iiitbhopal.ac.in/web/ProgramCourses.aspx. Retrieved in September 2020.

[25] https://www.nita.ac.in/IIITAgartala/. Retrieved in September 2020.

[26] https://www.iiitkottayam.ac.in/\#!/faculty. Retrieved in September 2020.

[27] https://www.iiitdm.ac.in/People/faculty.php. Retrieved in September 2020.

[28] http://faculty.iiitdmj.ac.in/. Retrieved in September 2020.

[29] http://iiitk.ac.in/Faculty/page. Retrieved in September 2020.

[30] https://nitdelhi.ac.in/?page id=15707. Retrieved in September 2020.

[31] http://www.nitgoa.ac.in/EMPBiodata.aspx. Retrieved in September 2020.

[32] http://www.nitmanipur.ac.in/EMPBiodata_New.aspx. Retrieved in September 2020.

[33] http://www.nitm.ac.in/p/heads-of-departments. Retrieved in September 2020.

[34] https://www.nitmz.ac.in/EMPBiodata.aspx. Retrieved in September 2020.

[35] https://nitnagaland.ac.in/. Retrieved in September 2020.

[36] http://www.nitp.ac.in/php/departments.php. Retrieved in September 2020.

[37] http://www.nitpy.ac.in/departments/index.html. Retrieved in September 2020.

[38] http://www.nitrr.ac.in/aboutenglish.php. Retrieved in September 2020.

[39] https://hss.nitsikkim.ac.in/faculty.php. Retrieved in September 2020.

[40] https://nitsri.ac.in/Department/department_facultylist.aspx?nDeptID=eg. Retrieved in September 2020.

[41] http://nituk.ac.in/pr.php. Retrieved in September 2020.

[42] http://www.svnit.ac.in/. Retrieved in September 2020.

[43] http://vnit.ac.in/academics/. Retrieved in September 2020.

[44] https://iitbhu.ac.in/\#. Retrieved in September 2020.

[45] https://www.iitgn.ac.in/faculty. Retrieved in September 2020.

[46] https://www.iitg.ac.in/\#. Retrieved in September 2020.

[47] https://iith.ac.in/people/faculty/. Retrieved in September 2020.

[48] https://iitpkd.ac.in/faculty-list. Retrieved in September 2020.

[49] https://www.iitgoa.ac.in/people.php?type=faculty\&year=\&dept=CAB. Retrieved in September 2020.

[50] http://iitj.ac.in/faculty/index.php?id=faculty members. Retrieved in September 2020.

[51] https://academic.iiti.ac.in/academic program.php. Retrieved in September 2020.

[52] https://www.iitbhilai.ac.in/index.php?pid=nav_department. Retrieved in September 2020.

[53] https://www.iitdh.ac.in/faculty.php. Retrieved in September 2020.

[54] https://iitjammu.ac.in/post/faculty-staff. Retrieved in September 2020.

[55] https://iittp.ac.in/people/faculty/humanities-and-social-sciences-department. Retrieved in September 2020. 
[56] https://www.iitp.ac.in/index.php/en-us/academics/faculty. Retrieved in September 2020.

[57] http://www.iitrpr.ac.in/academic. Retrieved in September 2020.

[58] https://www.iitmandi.ac.in/academics/index.php. Retrieved in September 2020.

[59] https://jindal.utdallas.edu/the-utd-top-100-business-school-research-rankings/worldRankings\#20152019. Retrieved in September 2020.

[60] http://www.ndtv.com/india-news/iit-iim-faculty-not-world-class-jairamramesh-456533. Retrieved in September 2020.

[61] Sahoo, B. K., Singh, R., Mishra, B., \& Sankaran, K. (2017). Research productivity in management schools of India during 1968-2015: A directional benefit-of-doubt model analysis. Omega, 66 (January), 118-139.

[62] https://www.ibef.org/industry/retail-india.aspx. Retrieved in August 2020.

[63] https://www.mckinsey.com/featured-insights/urbanization/urban-awakening-in-india. Retrieved in August 2020.

[64] https://www2.deloitte.com/content/dam/Deloitte/in/Documents/consumer-business/in-consumer-RLS2019-noexp.pdf. Retrieved in August 2020.

[65] Abivandana, Jain. (2011). Asia Investment Banking Research Report. India Retail Food, NORTHBRIDGE CAPITAL.

[66] Reardon, Thomas A. (2005). Retail companies as integrators of value-chains in developing countries. A report commissioned by Federal Ministry for Economic Cooperation and Development, Germany. Eschborn: Trade Matters series by GTZ Trade Programme.

[67] https://www.iiita.ac.in/academics/department/. Retrieved in September 2020.

[68] https://www.iiitm.ac.in/index.php/en/component/splms/?view=teachers. Retrieved in September 2020.

[69] https://www.nitj.ac.in/index.php/nitj_cinfo/index/55. Retrieved in September 2020.

[70] http://www.mnit.ac.in/dept mgmt/preprofile.php. Retrieved in September 2020.

[71] http://www.manit.ac.in/content/department-management-studies-dms. Retrieved in September 2020.

[72] http://www.mnnit.ac.in/index.php/department/mgmt-studies/mgmt-studiesfp. Retrieved in September 2020.

[73] https://www.nitap.ac.in/department/faculty?faculty=07005b74de. Retrieved in September 2020.

[74] https://www.nita.ac.in/NITAmain/departments/humanitiesDept/humanitiesFaculties.html. Retrieved in September 2020.

[75] https://nitdgp.ac.in/department/MS/people. Retrieved in September 2020.

[76] https://nith.ac.in/management-studies. Retrieved in September 2020.

[77] http://www.nitjsr.ac.in/academics/departments/facultylist.php?deptid=HUMANITIES. Retrieved in September 2020.

[78] https://som.nitk.ac.in/people. Retrieved in September 2020.

[79] https://www.nitkkr.ac.in/busi admin.php. Retrieved in September 2020.

[80] $\quad$ https://nitrkl.ac.in/Academics/AcademicDepartments/Faculty.aspx?fgdhwe34=U006U2Nob29s IG9mIE1hbmFnZW1lbnQ\%3d-9iEI7vg4nhs\%3d. Retrieved in September 2020.

[81] http://www.nits.ac.in/departments/management/management.php. Retrieved in September 2020.

[82] https://www.nitt.edu/home/academics/departments/management/people/faculty/. Retrieved in September 2020. 
[84] http://nitc.ac.in/index.php/?url=department/people/25/0/5. Retrieved in September 2020.

[85] https://nitandhra.ac.in/dept/shm/faculty. Retrieved in September 2020.

[86] https://www.iiests.ac.in/IIEST/AcaUnitDetails/HRM. Retrieved in September 2020.

[87] http://mgmt.iisc.ac.in/newwordpress/regular-faculty/. Retrieved in September 2020.

[88] https://www.iitbbs.ac.in/school-people-faculty.php?code=hs. Retrieved in September 2020.

[89] https://doms.iitm.ac.in/index.php/faculty-research/faculty-members. Retrieved in September 2020.

[90] http://dms.iitd.ac.in/all-faculty-members/?type=full-time-faculty. Retrieved in September 2020.

[91] http://iitk.ac.in/ime/regular-faculty. Retrieved in September 2020.

[92] https://som.iitkgp.ac.in/faculty.php. Retrieved in September 2020.

[93] http://www.som.iitb.ac.in/?p=122. Retrieved in September 2020.

[94] https://www.iitr.ac.in/departments/DM/pages/People+Faculty.html. Retrieved in September 2020.

[95] https://www.iitism.ac.in/index.php/Departments/faculties_ms. Retrieved in September 2020.

[96] https://www.nitie.edu/index.php/en/faculty-a-research/faculty-profile/alphabetical-order. Retrieved in September 2020.

[97] https://www.iima.ac.in/web/faculty/faculty-profiles/. Retrieved in September 2020.

[98] https://www.iimb.ac.in/faculty. Retrieved in September 2020.

[99] https://www.iimcal.ac.in/faculty/faculty-directory. Retrieved in September 2020.

[100] http://www.iiml.ac.in/faculty-profile. Retrieved in September 2020.

[101] https://www.iimidr.ac.in/faculty/full-time-faculty/. Retrieved in September 2020.

[102] https://iimk.ac.in/faculty/facultydirectory.php?letter=A. Retrieved in September 2020.

[103] https://iimraipur.ac.in/index.php/faculty?firstLetter=V\&Itemid=309. Retrieved in September 2020.

[104] https://www.iimranchi.ac.in/?page_id=421. Retrieved in September 2020.

[105] http://www.iimkashipur.ac.in/faculty/faculty-directory. Retrieved in September 2020.

[106] https://www.iimshillong.ac.in/faculty_research/faculty_dir.html. Retrieved in September 2020.

[107] https://www.iimu.ac.in/faculty-aamp-research/faculty/full-time-faculty. Retrieved in September 2020.

[108] https://www.iimrohtak.ac.in/index.php/faculty. Retrieved in September 2020.

[109] https://www.iimtrichy.ac.in/faculty-profile. Retrieved in September 2020.

[110] https://www.iimv.ac.in/faculty/full-time-faculty. Retrieved in September 2020.

[111] https://iimamritsar.ac.in/p/faculty.html. Retrieved in September 2020.

[112] https://iimbg.ac.in/faculty-research/faculty/. Retrieved in September 2020.

[113] http://www.iimj.ac.in/faculty-profile. Retrieved in September 2020.

[114] https://www.iimnagpur.ac.in/faculty/. Retrieved in September 2020.

[115] https://www.iimsambalpur.ac.in/en/faculty/full-time-faculty. Retrieved in September 2020.

[116] https://www.iimsirmaur.ac.in/iims/iim/faculty. Retrieved in September 2020.

[118] https://www.firstpost.com/business/blow-to-b-schools-93-of-management-graduates-unemployablesays-study-2753940.html. Retrieved in September 2020.

[119] DeAngelo, H., DeAngelo, L., \& Zimmerman, J. L. (2005). What's really wrong with US business schools?. Available

at SSRN: https://ssrn.com/abstract $=766404$ or 
http://dx.doi.org/10.2139/ssrn.766404.

[120] Jaskiewicz, P., Uhlenbruck, K., Balkin, D., \& Reay, T. (2013). Can nepotism be a source of competitive advantage? A social exchange perspective on types of nepotism. Family Business Review, 26(2), 121-139.

[121] Sroka, W., \& Vveinhardt, J. (2018, March). Nepotism and favouritism in the steel industry: a case study analysis. In Forum Scientiae Oeconomia, 6(1), 31-45.

[122] Arasli, H., \& Tumer, M. (2008). Nepotism, Favoritism and Cronyism: A study of their effects on job stress and job satisfaction in the banking industry of north Cyprus. Social Behavior and Personality: an International Journal, 36(9), 1237-1250.

[123] H. R., Ganesha., \& Aithal, P. S. (2020). Theory of Brick-and-Mortar Retailing in India (ToR-b). International Journal of Management, Technology, and Social Sciences (IJMTS), 5(2), 116-132.

[124] https://www.sbs.ox.ac.uk/research/oxford-institute-retail-management/research. Retrieved in September 2020.

[125] Aithal, P. S., \& Aithal, Shubhrajyotsna (2020). Analysis of the Indian National Education Policy 2020 towards Achieving its Objectives. International Journal of Management, Technology, and Social Sciences (IJMTS), 5(2), 19-41. DOI: http://doi.org/10.5281/zenodo.3988767.

$* * * * * * *$ 